\title{
Retrospective analysis of the effect of current clinical medications and clinicopathological factors on viral shedding in COVID-19 patients
}

\author{
YANFENG PAN $^{1 *}$, QINGQING LI ${ }^{1 *}, \mathrm{XUE} \mathrm{YU}^{1 *}$, QIANKUN LUO $^{2 *}, \mathrm{TAO} \mathrm{QIN}^{2 *}, \mathrm{NINGBO} \mathrm{XIN}^{3}$, \\ QIAN ZHANG ${ }^{4}$, XIANYANG LI ${ }^{5}$, XINWEI DU ${ }^{6}$, QINGXIA ZHAO ${ }^{3}$ and LI SUN ${ }^{7}$ \\ ${ }^{1}$ Department of Infectious Diseases, The First Affiliated Hospital of Zhengzhou University; \\ ${ }^{2}$ Department of Hepatobiliary and Pancreatic Surgery, Zhengzhou University People's Hospital, \\ Henan Provincial People's Hospital; ${ }^{3}$ Department of Infectious Diseases, Zhengzhou Sixth People's Hospital; \\ ${ }^{4}$ Department of Infectious Diseases, Henan Provincial People's Hospital, Zhengzhou, Henan 450000; \\ ${ }^{5}$ Department of Infectious Diseases, Shenqiu County People's Hospital, Zhoukou, Henan 466300; \\ ${ }^{6}$ Department of Infectious Diseases, The People's Hospital of Suzhou New District, Suzhou, Jiangsu 205011; \\ ${ }^{7}$ Department of Clinical Laboratory, The First Affiliated Hospital of Zhengzhou University, \\ Zhengzhou, Henan 450000, P.R. China
}

Received June 13, 2020; Accepted September 23, 2020

DOI: $10.3892 /$ br.2020.1375

\begin{abstract}
The aim of the present study was to identify the risk factors associated with prolonged shedding in patients with coronavirus disease 2019 (COVID-19), and to evaluate the effects of current clinical and clinicopathological factors on viral shedding in patients. A total of 186 COVID-19 inpatients were enrolled in this multicentre retrospective analysis. Detailed clinical data of each patient were collected, and the factors that affected the duration of viral shedding were retrospectively analysed. The median duration of viral shedding in the 186 COVID-19 patients was 13 days. The median duration of viral shedding was 12 days in non-severe patients, and 17 days in severe patients, and there was a significant difference between the two groups $(\mathrm{P}<0.001)$. Multi-factor regression analysis suggested that the onset-hospitalization
\end{abstract}

Correspondence to: Professor Yanfeng Pan, Department of Infectious Diseases, The First Affiliated Hospital of Zhengzhou University, 1 Jianshe East Road, Jinshui, Zhengzhou, Henan 450000, P.R. China

E-mail: panfirstfeng@163.com

Professor Tao Qin, Department of Hepatobiliary and Pancreatic Surgery, Zhengzhou University People's Hospital, Henan Provincial People's Hospital, 7 Weiwu Road, Jinshui, Zhengzhou, Henan 450000, P.R. China

E-mail: goodfreecn@163.com

*Contributed equally

Key words: COVID-19, SARS-CoV-2, viral shedding, lopinavir/ ritonavir, corticosteroid interval [odds ratio (OR), 1.27; 95\% confidence interval (CI), 1.15-1.41; $\mathrm{P}<0.001]$ and comorbidity with a chronic disease (OR, 2.43; 95\% CI, 1.14-5.17; $\mathrm{P}=0.021$ ) were independent risk factors for prolonged viral shedding, whereas lopinavir/ritonavir (LPV/r) was an independent protective factor (OR, 0.28; 95\% CI, 0.11-0.75; $\mathrm{P}=0.011$ ). Spearman's rank correlation analysis showed that the onset-drug interval was positively correlated with the duration of viral shedding $(r=0.446 ; \mathrm{P}<0.0001)$. Umifenovir, and low and short courses of glucocorticoids were not associated with prolonged viral shedding. The prolonged viral shedding was the initial causative factor of persistent aggravation of the patient's conditions. The interval between presentation of symptoms and hospitalization as well as complications with a comorbid chronic disease were independent risk factors for prolonged viral shedding. LPV/r shortened the duration of viral shedding, and the smaller the interval between presentation and LPV/r onset was, the faster viral shedding occurred.

\section{Introduction}

Coronavirus disease 2019 (COVID-19), caused by infection from severe acute respiratory syndrome-coronavirus 2 (SARS-CoV-2), has become a global pandemic and a serious global public health emergency (1). The prevention and control of COVID-19 is a considerable challenge being faced by numerous governments worldwide, and this is complicated by the high transmission efficiency, high mortality rate, general susceptibility of the population, and the absence of effective drugs and vaccines $(2,3)$. As the pathology of COVID-19 is similar to that of Middle East respiratory syndrome coronavirus (MERS-CoV) and SARS-CoV infection $(4,5)$, drugs identified to be effective for these previous diseases, as well as antivirals screened from in vitro experiments, are 
being assessed or used clinically without sufficient clinical evidence. These drugs include IFN- $\alpha$ and ribavirin, as well as lopinavir/ritonavir (LPV/r) and Umifenovir as antiviral drugs. Several studies have described the effects of antiviral on the duration of viral shedding (6-8) and other studies have assessed the differences in the duration of viral shedding between patients with different degrees of severity of infection (9). Recently, obesity was identified as a risk factor for increased COVID-19 prevalence, severity and lethality (10), and modulation of zinc status may be beneficial in the management COVID-19 (11). However, these studies did not consider the effects of both clinical and clinicopathological factors on the duration of viral shedding. In the present study, detailed data on inpatients with definite clinical outcomes between January 20, 2020 and March 20, 2020 was collected and reviewed the duration of viral shedding in COVID-19 infected patients in order to evaluate the impact of current clinical and clinicopathological factors on viral shedding. Clinicopathological factors refers to the patient's general characteristics and medical history that are not related to this hospitalization, such as sex, age, comorbid chronic diseases and onset-hospitalization interval.

\section{Materials and methods}

Study design. Data on SARS-CoV-2 nucleic acid-positive hospitalized patients were collected between January 20, 2020 and March 20, 2020. Reverse transcription polymerase chain reaction (RT-PCR) was used to test for SARS-CoV-2 nucleic acids from respiratory tract secretions and throat swab specimens. The patients underwent a RT-PCR test every 3 days during the first week of hospitalization, and a nucleic acid test every day after a week of hospitalization. A retrospective analysis of the SARS-CoV-2 shedding duration and the effect of currently used drugs on the duration of viral shedding was performed. This study was exempt from the need to obtain patient consent due to the retrospective nature of the study, and was approved by the Medical Ethics Committee of Zhengzhou University (approval no. 2020-KY-162).

Data collection. The age, sex, clinical symptoms, onset-drug interval, onset-hospitalization interval, therapeutic drugs and prognosis of each patient were collected. The median age of the 186 patients was 46.5 years (age range, 5-94 years). A total of $105(56.5 \%)$ cases were males and $81(43.5 \%)$ were females. Onset was defined as the earliest time when clinical symptoms appeared. The duration of viral shedding was defined as the time from onset to the last positive test for SARS-CoV-2. The criteria for severe cases (including critical) was defined as follows: Breathing significantly faster, $>30$ times per minute in a resting state; blood oxygen saturation $<90 \%$, or blood oxygen saturation notably decreased in the analysis of arterial blood gas; and lung image showing $>50 \%$ apparent progression of lesions within 24-48 h. Non-severe cases were diagnosed with mild respiratory infection symptoms (defined as fever $<39^{\circ} \mathrm{C}$, no breathing difficulties, blood oxygen saturation $\geq 90 \%$ ), without visible radiological changes of the chest. The application of drugs was defined as patients treated with a drug for $\geq 3$ days.
Statistical analysis. All statistical analysis was performed using SPSS version 21.0 (SPSS, Inc.). Categorical variables were expressed as percentages. Normally distributed continuous variables are shown as the mean \pm standard deviation, and were compared using a Student's t-test. Non-normally distributed continuous variables are presented as the median, and a rank sum test was used for comparison. Significant risk factors identified by univariate analyses were further analysed by multivariate logistic regressions to identify independent risk factors associated with a prolonged duration of SARS-CoV-2 shedding [odds ratio (OR), 95\% confidence interval (CI)]. Rank correlation analysis was used to analyse the correlation between onset-drug interval of LPV/r and the duration of viral shedding. A two-sided $\mathrm{P}<0.05$ was considered to indicate a statistically significant difference.

\section{Results}

Characteristics and treatments. A total of 133 non-severe cases $(71.5 \%)$ and $53(28.5 \%)$ severe cases were enrolled in this study, including 10 deaths (5.4\%). A total of 54 patients $(29.0 \%)$ had a comorbid chronic disease, and 31 patients exhibited $\geq 1$ comorbid disease, including 29 with hypertension, 18 with diabetes, 15 with coronary heart disease and 7 with chronic lung disease. The median onset-hospitalization interval for the 186 patients was 5 days [interquartile range (IQR) 2-8 days]. LPV/r (adults, $400 \mathrm{mg} / 100 \mathrm{mg}$ bid po; children, $200 \mathrm{mg} / 50 \mathrm{mg}$ bid po) was administered to 158 patients (84.9\%) during hospitalization. A total of 140 patients had a clear onset-drug interval, with a median period of 7 days (IQR, 4-10 days). Umifenovir (200 mg tid po) was administered to 44 (23.7\%) patients. A total of 18 patients $(9.7 \%)$ were treated with ribavirin (500 $\mathrm{mg}$ bid ivggt) during hospitalization. A total of 30 patients $(16.1 \%)$ were treated with a corticosteroid during hospitalization, at doses of ranging from 40-120 mg; however, although the highest dose was $120 \mathrm{mg}$ per day, the majority of patients received $<80 \mathrm{mg} /$ day.

Duration of viral shedding. The duration of SARS-COV-2 shedding was 3-40 days, and the median period was 13 days (IQR, 10-19 days). The median duration of viral shedding in non-severe case was 12 days (IQR, 8-17 days), and the longest duration was 39 days. The median duration of viral shedding in severe case was 17 days (IQR, 12-23 days), and the longest duration was 40 days; there was a significant difference $(\mathrm{P}<0.001)$ between the two groups. In 5 deaths, the nucleic acid test remained positive. The different characteristics of the COVID-19 patients with the duration of viral shedding are outlined in Table I.

Analysis of influencing factors on the duration of viral RNA shedding. As the median duration of SARS-CoV-2 shedding was 13 days, a 14-day cut-off was used. A 12 or 13-day cut-off was not appropriate as the 12 or 13-day cut-off was not statistically significant, although there was a difference. This study focused on analysing the factors influencing viral shedding duration ( $\leq 14$ and $>14$ days). With the duration of viral shedding as a dependent variable, univariate analysis of sex, age, onset-hospitalization interval, whether the patient had a comorbid chronic disease, ribavirin use, lopinavir/ritonavir 
Table I. Characteristics of COVID-19 patients and the duration of viral shedding.

\begin{tabular}{|c|c|c|c|}
\hline \multirow[b]{2}{*}{ Factors } & \multicolumn{2}{|c|}{ Viral shedding duration after illness onset } & \multirow[b]{2}{*}{ P-value } \\
\hline & $\leq 14$ days, $\mathrm{n}=115$ & $>14$ days, $\mathrm{n}=71$ & \\
\hline Age, years, mean \pm standard deviation & $44.35 \pm 17.44$ & $51.39 \pm 18.15$ & $0.009^{\mathrm{b}}$ \\
\hline Sex, n $(\%)$ & & & 0.98 \\
\hline Male & $65(56.5)$ & $40(56.3)$ & \\
\hline Female & $50(43.5)$ & $31(43.7)$ & \\
\hline Onset-hospitalization interval, days (IQR) & $4(2-7)$ & $7(3-11)$ & $<0.001$ \\
\hline Comorbid chronic disease, $\mathrm{n}(\%)$ & & & $0.005^{\mathrm{b}}$ \\
\hline Yes & $25(21.7)$ & $29(40.8)$ & \\
\hline No & $90(78.3)$ & $42(59.2)$ & \\
\hline Ribavirin use, n (\%) & & & $0.002^{\mathrm{b}}$ \\
\hline Yes & $5(4.3)$ & $13(18.3)$ & \\
\hline No & $110(95.7)$ & $58(81.7)$ & \\
\hline Lopinavir/ritonavir use, n (\%) & & & $<0.001$ \\
\hline Yes & $106(92.2)$ & $52(73.2)$ & \\
\hline No & $9(7.8)$ & $19(26.8)$ & \\
\hline Umifenovir use, n (\%) & & & $0.028^{\mathrm{a}}$ \\
\hline Yes & $21(18.3)$ & $23(32.4)$ & \\
\hline No & $94(81.7)$ & $48(67.6)$ & \\
\hline Corticosteroid use, n (\%) & & & $0.007^{\mathrm{b}}$ \\
\hline Yes & $12(10.4)$ & $18(25.4)$ & \\
\hline No & $103(89.6)$ & $53(74.6)$ & \\
\hline
\end{tabular}

${ }^{\mathrm{a}} \mathrm{P}<0.05,{ }^{\mathrm{b}} \mathrm{P}<0.01$. IQR, interquartile range; COVID-19, coronavirus disease 19.

use, Umifenovir use and corticosteroid use were defined as independent variables and logistic stepwise multiple regression analysis was performed.

Univariate analysis showed that the factors significantly associated with prolonged viral shedding were age, onset-hospitalization interval, comorbid chronic disease, use of LPV/r, use of ribavirin, use of Umifenovir and use of a corticosteroid. However, sex was not associated with prolonged viral shedding.

For the multivariate analysis, four parameters were included in the final logistic regression model: Onset-hospitalization interval, comorbid chronic disease, ribavirin use and LPV/r use. Multiple regression analysis suggested that the onset-hospitalization interval (OR, 1.27, 95\% CI, 1.15-1.41; $\mathrm{P}<0.001)$, comorbid chronic disease (OR, 2.43, 95\% CI, 1.14-5.17; $\mathrm{P}=0.021)$ and ribavirin use $(\mathrm{OR}, 5.97,95 \% \mathrm{CI}$, 1.77-20.09; $\mathrm{P}=0.004)$ were independent risk factors for prolonged viral shedding. LPV/r was an independent protective factor (OR, $0.28,95 \% \mathrm{CI}, 0.11-0.75 ; \mathrm{P}=0.011)$ that could shorten the duration of viral shedding (Table II).

Relationship between duration of SARS-CoV-2 shedding and onset-drug interval of LPV/r. A total of 140 patients were administered LPV/r, and the onset-drug interval was positively correlated with the duration of viral shedding (rank correlation test $r=0.446 ; \mathrm{P}<0.0001)$. The longer the onset-drug interval of $\mathrm{LPV} / \mathrm{r}$ was, the longer the duration of viral shedding was (Fig. 1).

\section{Discussion}

COVID-19 is a newly discovered infectious disease with no specific drug treatments and asymptomatic patients have been identified as a considerable source of infection (12). At present, several drugs are being used based on previous experience in the treatment of similar coronavirus epidemics such as SARS and MERS; however, the efficacy of these drugs require urgent verification. Therefore, in the present study, a multicentre retrospective analysis of 186 patients was performed to explore the effects of therapeutic drugs and clinicopathological factors on the duration of SARS-CoV-2 viral shedding.

The duration of viral shedding is used as an index to measure infectivity and evaluate the efficacy of antiviral drugs (13-15). The median duration of SARS-CoV-2 shedding was 13 days (IQR, 10-19 days), with a maximum of 40 days. The results showed that the duration of SARS-CoV-2 shedding was generally long; this indicated a long period where a person is potentially infectious, and thus requires prolonged isolation, in which case, the course of antiviral treatment should be extended accordingly. The median viral shedding period for severe patients was 17 days (IQR, 12-23 days), which was significantly longer than the 12 days (IQR, 8-17 days) of non-severe patients. Since viral load is the initial factor exhibiting persistent aggravation, early antiviral therapy is very important in theory.

In the present study, 44 patients $(23.7 \%)$ were treated with Umifenovir (200 mg tid po), and the administration 
Table II. Multivariate analysis of factors associated with the duration of viral shedding of COVID-19.

\begin{tabular}{|c|c|c|c|c|c|c|}
\hline \multirow[b]{2}{*}{ Variable } & \multicolumn{3}{|c|}{ Multivariable analysis } & \multicolumn{3}{|c|}{ Stepwise analysis } \\
\hline & OR & $95 \% \mathrm{CI}$ & $\mathrm{P}$-value & OR & $95 \% \mathrm{CI}$ & P-value \\
\hline Age & 1.02 & $1.01-1.04$ & 0.010 & - & - & - \\
\hline Sex & 1.01 & $0.56-1.83$ & 0.980 & - & - & - \\
\hline Onset-hospitalization interval & 1.22 & $1.11-1.33$ & $<0.001$ & 1.27 & $1.15-1.41$ & $<0.001^{\mathrm{c}}$ \\
\hline Comorbid chronic disease & 2.49 & $1.30-4.75$ & 0.006 & 2.43 & $1.14-5.17$ & $0.021^{\mathrm{a}}$ \\
\hline Using ribavirin & 4.93 & $1.68-14.51$ & 0.004 & 5.97 & $1.77-20.09$ & $0.004^{\mathrm{b}}$ \\
\hline Using lopinavir/ritonavir & 0.23 & $0.10-0.55$ & 0.001 & 0.28 & $0.11-0.75$ & $0.011^{\mathrm{a}}$ \\
\hline Using Umifenovir & 2.15 & $1.08-4.26$ & 0.029 & - & - & - \\
\hline Using corticosteroid & 2.92 & $1.31-6.50$ & 0.009 & - & - & - \\
\hline
\end{tabular}

${ }^{\mathrm{a}} \mathrm{P}<0.05,{ }^{\mathrm{b}} \mathrm{P}<0.01,{ }^{\mathrm{c}} \mathrm{P}<0.001$. OR, odds ratio; $\mathrm{CI}$, confidence interval.

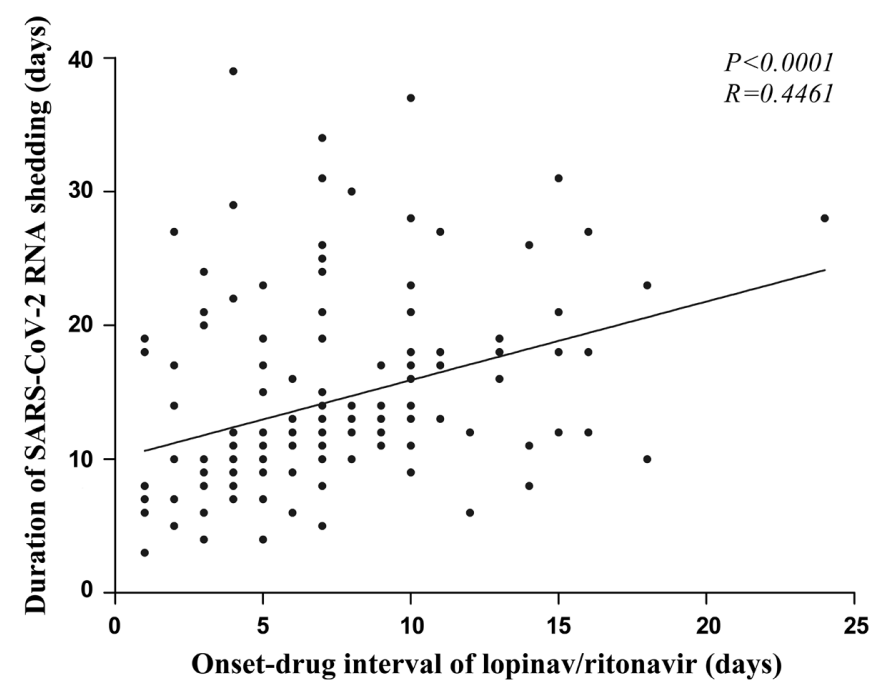

Figure 1. Relationship between duration of SARS-CoV-2 shedding and onset-drug interval of lopinavir/ritonavir. SARS-CoV2, severe acute respiratory syndrome-coronavirus 2 .

of Umifenovir was relatively early. Multivariate analysis showed that Umifenovir did not affect SARS-CoV-2 shedding. This finding suggests that Umifenovir has no beneficial anti-SARS-CoV-2 effect.

The results of multivariate analysis showed that ribavirin was a high-risk factor for prolonging the time of viral shedding. This was an unexpected result that differed from a previous study (16), and this may have been caused by data bias. Additional clinical trials, particularly randomized controlled clinical trials, are required to further evaluate the effect of ribavirin on patients with SARS-CoV-2.

As the most widely used anti-inflammatory and immunosuppressive agents in clinical practice, corticosteroids serve an important role in the treatment of critically ill patients (17). However, whether and how to use them for the treatment of COVID-19 remains controversial. Previous studies have shown that corticosteroids may prolong the duration of viral shedding and may facilitate adverse effects such as secondary infection and delirium; however, corticosteroids has been shown to also reduce mortality in patients with severe COVID-19 (18-20). The present study found no evidence suggesting that corticosteroid treatment prolonged viral shedding time. In China, a low dose and short course of corticosteroid therapy is generally used on severe and critical COVID-19 patients (21). In the present study, 30 patients were treated with 40-120 mg corticosteroids during hospitalization. The dose is generally $<80 \mathrm{mg}$ and the course of treatment is $\sim 7$ days. Therefore, for critically ill patients, small doses and short courses of a corticosteroid may be considered under special circumstances.

In the total 186 patients, the median time of onset-hospitalization interval was 5 days (IQR, 2-8 days). Multivariate regression analysis found that the onset-hospitalization interval was an independent risk factor for prolonged viral shedding time. Therefore, early hospitalization of COVID-19 patients can shorten the duration of viral shedding and improve the prognosis of patients, whilst also reducing the infectivity of the patient.

Complications with a comorbid chronic disease was also an independent risk factor for prolonged viral shedding. COVID-19 patients with long-term comorbid chronic diseases may have relatively low immunity; these patients were susceptible to severe pneumonia and thus had a poor prognosis (22).

LPV has been used in combination with ritonavir (a booster) in HIV infection therapy and prevention, and it functions as an antiretroviral protease inhibitor (23). LPV/r has shown efficacy in the treatment of SARS-CoV and MERS (24-26). SARS-CoV-2 is a coronavirus similar to SARS-CoV and MERS (27); however, the effects of LPV/r on SARS-CoV-2 remains unclear. In a recent retrospective study of risk factors associated with death in hospitalized COVID-19 patients in Wuhan, Zhou et al (14) found no reduction in the duration of viral shedding following LPV/r treatment. In critically ill patients with COVID-19, Cao et al (28) found that LPV/r did not significantly accelerate clinical improvement, reduce mortality, or reduce the viral RNA load detected in the throat. These results may be due to the small sample sizes, single factor retrospective analysis, or the severity of the patients' illness. More recent studies have shown that hospital mortality rates were lower in the LPV/r group (29), and the lack of $\mathrm{LPV} / \mathrm{r}$ treatment was independently associated with prolonged 
SARS-CoV-2 RNA shedding (30). The multiple factor regression analysis performed in the present study showed that $\mathrm{LPV} / \mathrm{r}$ shortened the duration of SARS-CoV-2 shedding. In the study by Cao et al (28), all the patients had severe symptoms, the number of cases was small and treatment with LPV/r started relatively later compared with the present study. In contrast, in the present study, the data on 158 patients who used LPV/r and 28 patients who did not was collected, and the median onset-drug interval was only 7 days (IQR, 4-10 days). The strengths of the present study include a larger number of cases, which consisted primarily of patients with non-severe patients and the earlier administration of antivirals.

To further evaluate the effect of early antiviral treatment with LPV/r on SARS-CoV-2 shedding, the correlation between the onset-drug interval and the duration of viral shedding was assessed, and this showed a significant positive correlation. The longer the onset-drug interval of LPV/r, the longer the duration of viral shedding; these findings suggested that early antiviral treatment was important for favourable outcomes. A previous study showed that the timing of LPV/r combined with hydroxychloroquine treatment initiation did not seem to affect the clinical course of COVID-19 patients (31), in contrast to the results of the present study. Thus, additional studies with larger cohorts are required to demonstrate the efficacy of LPV/r on COVID-19 infection.

The present study has limitations in that it was a retrospective analysis, several factors were included, and the sample size was limited. Although the research factors were screened by single factor analysis and stepwise regression, the results still require further verification in large-scale prospective studies.

In conclusion, the results of the present study showed that the duration of viral shedding of SARS-COV-2 based on treatment, and prolonged viral shedding was an important factor causing persistent aggravation of the patient's condition. The onset-hospitalization interval and complication with comorbid chronic diseases were independent risk factors for prolonged viral shedding. LPV/r application shortened the duration of viral shedding, and the earlier LPV/r was used, the shorter the duration of viral shedding was. These results suggest that COVID-19 patients should be hospitalized and receive antiviral treatment as early as possible, and the use of LPV/r is a viable option.

\section{Acknowledgements}

Not applicable.

\section{Funding}

No funding was received.

\section{Availability of data and materials}

The datasets used during the present study are available from the corresponding author upon reasonable request.

\section{Authors' contributions}

YP contributed to the conception and design of study and the analysis and interpretation of data. QLi contributed to the acquisition, analysis and interpretation of data and manuscript review. XY contributed to the acquisition, analysis and interpretation of data. QLuo contributed to the interpretation of data and manuscript review. TQ, NX, QZhang, XL, XD, QZhao and LS contributed to the acquisition of data. All authors read and approved the final manuscript.

\section{Ethics approval and consent to participate}

This study was exempt from the need to obtain patient consent due to the retrospective nature of the study, and was approved by the Medical Ethics Committee of Zhengzhou University (approval no. 2020-KY-162).

\section{Patient consent for publication}

Not applicable.

\section{Competing interests}

The authors declare that they have no competing interests.

\section{References}

1. Sohrabi C, Alsafi Z, O'Neill N, Khan M, Kerwan A, Al-Jabir A, Iosifidis $\mathrm{C}$ and Agha R: World Health Organization declares global emergency: A review of the 2019 Novel Coronavirus (COVID-19). Int J Surg 76: 71-76, 2020.

2. Dong L, Hu S and Gao J: Discovering drugs to treat coronavirus disease 2019 (COVID-19). Drug Discov Ther 14: 58-60, 2020.

3. Calina D, Docea AO, Petrakis D, Egorov AM, Ishmukhametov AA, Gabibov AG, Shtilman MI,Kostoff R, Carvalho F, Vinceti M, et al: Towards effective COVID-19 vaccines: Updates, perspectives and challenges (Review). Int J Mol Med 46: 3-16, 2020.

4. Zhou P, Yang XL, Wang XG, Hu B, Zhang L, Zhang W, Si HR, Zhu Y, Li B, Huang CL, et al: A pneumonia outbreak associated with a new coronavirus of probable bat origin. Nature 579: 270-273, 2020 .

5. Sarzi-Puttini P, Giorgi V, Sirotti S, Marotto D, Ardizzone S, Rizzardini G, Antinori S and Galli M: COVID-19, cytokines and immunosuppression: What can we learn from severe acute respiratory syndrome? Clin Exp Rheumatol 38: 337-342, 2020.

6. Zhang Z, Wang S, Tu X, Peng X, Huang Y, Wang L, Ju W, Rao J, Li X, Zhu D, et al: A comparative study on the time to achieve negative nucleic acid testing and hospital stays between danoprevir and Lopinavir/Ritonavir in the treatment of patients with COVID-19. J Med Virol: Jun 5, 2020 (Epub ahead of print).

7. Zuo Y, Liu Y, Zhong Q, Zhang K, Xu Y and Wang Z: Lopinavir/ritonavir and interferon combination therapy may help shorten the duration of viral shedding in patients with COVID-19: A retrospective study in two designated hospitals in Anhui, China. J Med Virol: Jun 3, 2020 (Epub ahead of print).

8. Nitulescu GM, Paunescu H, Moschos SA, Petrakis D, Nitulescu G, Ion GND, Spandidos DA, Nikolouzakis TK, Drakoulis $\mathrm{N}$ and Tsatsakis A: Comprehensive analysis of drugs to treat SARS-CoV-2 infection: Mechanistic insights into current COVID-19 therapies (Review). Int J Mol Med 46: 467-488, 2020

9. Du X, Yu X, Li Q, Li X, Qin T, Luo Q, Wang M, Jiang M, Bai L, Wang $X$ and Pan Y: Duration for carrying SARS-CoV-2 in COVID-19 patients. J Infect 81: e78-e79, 2020.

10. Petrakis D, Margină D, Tsarouhas K, Tekos F, Stan M, Nikitovic D, Kouretas D, Spandidos DA and Tsatsakis A: Obesity-a risk factor for increased COVID-19 prevalence, severity and lethality. Int J Mol Med 22: 9-19, 2020.

11. Skalny AV, Rink L, Ajsuvakova OP, Aschner M, Gritsenko VA, Alekseenko SI, Svistunov AA, Petrakis D, Spandidos DA, Aaseth J, et al: Zinc and respiratory tract infections: Perspectives for COVID-19 (Review). Int J Mol Med 46: 17-26, 2020.

12. Pan Y, Yu X, Du X, Li Q, Li X, Qin T, Wang M, Jiang M, Li J, $\mathrm{Li} \mathrm{W}$, et al: Epidemiological and clinical characteristics of 26 asymptomatic severe acute respiratory syndrome coronavirus 2 carriers. J Infect Dis 221: 1940-1947, 2020. 
13. Young BE, Ong SWX, Kalimuddin S, Low JG, Tan SY, Loh J, Ng OT, Marimuthu K, Ang LW, Mak TM, et al: Epidemiologic features and clinical course of patients infected With SARS-CoV-2 in Singapore. JAMA 323: 1488-1494, 2020

14. Zhou F, Yu T, Du R, Fan G, Liu Y, Liu Z, Xiang J, Wang Y, Song B, Gu X, et al: Clinical course and risk factors for mortality of adult inpatients with COVID-19 in Wuhan, China: A retrospective cohort study. Lancet 395: 1054-1062, 2020.

15. Tsang TK, Cowling BJ, Fang VJ, Chan KH, Ip DK, Leung GM, Peiris JS and Cauchemez S: Influenza $A$ virus shedding and infectivity in households. J Infect Dis 212: 1420-1428, 2015.

16. Tong S, Su Y, Yu Y, Wu C, Chen J, Wang S and Jiang J: Ribavirin therapy for severe COVID-19: A retrospective cohort study. Int J Antimicrob Agents 56: 106114, 2020.

17. Sibila O, Agustí $\mathrm{C}$ and Torres A: Corticosteroids in severe pneumonia. Eur Respir J 32: 259-264, 2008

18. Prescott HC and Rice TW: Corticosteroids in COVID-19 ARDS Evidence and hope during the pandemic. JAMA: Sep 2, 2020 (Epub ahead of print).

19. WHO Rapid Evidence Appraisal for COVID-19 Therapies (REACT) Working Group; Sterne JAC, Murthy S, Diaz JV, Slutsky AS, Villar J, Angus DC, Annane D, Azevedo LCP, Berwanger $\mathrm{O}$, et al: Association between administration of systemic corticosteroids and mortality among critically ill patients with COVID-19: A meta-analysis. JAMA: Sep 2, 2020 (Epub ahead of print).

20. Lee N, Allen Chan KC, Hui DS, Ng EK, Wu A, Chiu RW, Wong VW, Chan PK, Wong KT, Wong E, et al: Effects of early corticosteroid treatment on plasma SARS-associated Coronavirus RNA concentrations in adult patients. J Clin Virol 31: 304-309, 2004.

21. Zhao JP, Hu Y, Du RH, Chen ZS, Jin Y, Zhou M, Zhang J, Qu JM and Cao B: Expert consensus on the use of corticosteroid in patients with 2019-nCoV pneumonia. Zhonghua Jie $\mathrm{He} \mathrm{Hu} \mathrm{Xi} \mathrm{Za}$ Zhi 43: 183-184, 2020 (In Chinese).

22. Guan WJ, Liang WH, Zhao Y, Liang HR, Chen ZS, Li YM, Liu XQ, Chen RC, Tang CL, Wang T, et al: Comorbidity and its impact on 1590 patients with Covid-19 in China: A nationwide analysis. Eur Respir J 55: 2000547, 2020.

23. Meini S, Pagotto A, Longo B, Vendramin I, Pecori D and Tascini C: Role of Lopinavir/ritonavir in the treatment of Covid-19: A review of current evidence, guideline recommendations, and perspectives. J Clin Med 9: 2050, 2020.
24. Chu CM, Cheng VC, Hung IF, Wong MM, Chan KH, Chan KS, Kao RY, Poon LL, Wong CL, Guan Y, et al: Role of lopinavir/ritonavir in the treatment of SARS: Initial virological and clinical findings. Thorax 59: 252-256, 2004.

25. Sheahan TP, Sims AC, Leist SR, Schäfer A, Won J, Brown AJ, Montgomery SA, Hogg A, Babusis D, Clarke MO, et al: Comparative therapeutic efficacy of remdesivir and combination lopinavir, ritonavir, and interferon beta against MERS-CoV. Nat Commun 11: 222, 2020.

26. Chan JF, Yao Y, Yeung ML, Deng W, Bao L, Jia L, Li F, Xiao C, Gao H, Yu P, et al: Treatment with lopinavir/ritonavir or interferon- $\beta 1 \mathrm{~b}$ improves outcome of MERS-CoV infection in a nonhuman primate model of common marmoset. J Infect Dis 212: 1904-1913, 2015.

27. Zhu N, Zhang D, Wang W, Li X, Yang B, Song J, Zhao X, Huang B, Shi W, Lu R, et al: A novel coronavirus from patients with pneumonia in China, 2019. N Engl J Med 382: 727-733, 2020.

28. Cao B, Wang Y, Wen D, Liu W, Wang J, Fan G, Ruan L, Song B, Cai Y, Wei M, et al: A trial of lopinavir-ritonavir in adults hospitalized with severe covid-19. N Engl J Med 382: 1787-1799, 2020.

29. Karolyi M, Pawelka E, Mader T, Omid S, Kelani H, Ely S, Jilma B, Baumgartner S, Laferl H, Ott C, et al: Hydroxychloroquine versus lopinavir/ritonavir in severe COVID-19 patients: Results from a real-life patient cohort. Wien Klin Wochenschr: Aug 10, 2020 (Epub ahead of print).

30. Yan D, Liu XY, Zhu YN, Huang L, Dan BT, Zhang GJ and Gao YH: Factors associated with prolonged viral shedding and impact of lopinavir/ritonavir treatment in hospitalised non-critically ill patients with SARS-CoV-2 infection. Eur Respir J 56: 2000799, 2020

31. Giacomelli A, Pagani G, Ridolfo AL, Oreni L, Conti F, Pezzati L, Bradanini L, Casalini G, Bassoli C, Morena V, et al: Early administration of lopinavir/ritonavir plus hydroxychloroquine does not alter the clinical course of SARS-CoV-2 infection: A retrospective cohort study. J Med Virol: Aug 10, 2020 (Epub ahead of print). 